\section{References}

${ }^{1}$ Marshall, W A, and Tanner, J M, in Scientific Foundations of Paediatrics, ed, J A Davis and J Dobbing, p 124, London, Heinemann, 1974.

${ }^{2}$ Milligan, D, Drife, J O, and Short, R V, British Medical fournal, 1975, 4, 494.

${ }^{3}$ Hytten, F E, British Medical fournal, 1954, 1, 912.

${ }^{4}$ Ford, C S, and Beach, F A, Patterns of Sexual Behaviour, London, Eyre and Spottiswoode, 1952.

${ }^{5}$ Gunther, M, Lancet, 1955, 2, 575.
${ }^{6}$ Klaus, M H, and Kennell, J H, Maternal-Infant Bonding. St. Louis, C V Mosby, 1976.

7 Tindal, J S, Handbook of Physiology, vol 4, section 7, part 1, p 257. Washington, American Physiological Society, 1972.

8 Tyson, J E, Friesen, H, and Anderson, M, Science, 1972, 177, 897.

${ }^{9}$ Kann, G, and Martinet, J, Nature, 1975, 257, 63.

10 Short, R V, Proceedings of the Royal Society, Series B, 1976, 195, 3.

11 Hinde, R A, Bell, R Q, and Steel, R, Animal Behaviour, 1963, 11, 553.

12 Bliss, C I, Statistics in Biology, vol 2. New York, McGraw-Hill, 1970.

(Accepted 2 March 1977)

\title{
Intravenous tyramine response in migraine before and during treatment with indoramin
}

\author{
K GHOSE， A COPPEN， D CARROLL
}

British Medical fournal, 1977, 1, 1191-1193

\section{Summary}

We studied the response of 31 migraine sufferers (20 women, 11 men) to intravenous tyramine (the tyraminedose/pressor response test). Patients were treated either with placebo tablets or indoramin, an alpha-adrenergic blocking agent, in a double-blind crossover trial. We found that patients with migraine required significantly less tyramine to increase their systolic blood pressure by $30 \mathrm{~mm} \mathrm{Hg}$ when compared with matched controls. Indoramin significantly increased the amount of tyramine needed to raise the systolic blood pressure among migraine sufferers and reduced the incidence of posttyramine migraine from $46 \%$ while patients were on placebo tablets to $8 \%$ when they were receiving indoramin. There was no association between tyramine sensitivity and a history of premenstrual or dietary migraine, nor was there a significant difference in the incidence of post-tyramine migraine between men and women. We conclude that the intravenous tyramine test may be valuable in assessing migraine sufferers who will respond to an alpha-advenergic blocking agent such as indoramin.

\section{Introduction}

There are conflicting reports both about the role of the biogenic amines and their receptors in the aetiology of migraine, ${ }^{1-4}$ and about the sensitivity of patients with migraine to tyramine given by mouth. ${ }^{5}{ }^{6}$ Secutari ${ }^{1}$ reported decreased central serotonin activity in migraine sufferers and postulated that a supersensitivity to monoamines may be associated with the complaint. Herraro and Marino $^{2}$ postulated increased concentrations of circulating noradrenaline and tyramine during migraine attacks. Sandler et $a l^{7}$ have reported decreased platelet

Medical Research Council Neuropsychiatry Laboratory, West Park Hospital, Epsom, Surrey

KARABI GHOSE, MRCP, senior research registrar

ALEC COPPEN, FRCPSYCH, MRCP, director

Regional Neurological Unit, Royal Surrey County Hospital, Guildford, Surrey

DESMOND CARROLL, MD, FRCP, consultant neurologist monoamine oxidase activity in patients with migraine. Hence, if migraine is associated with either increases in circulating monoamines, or receptor sensitivity, or decreased monoamine oxidase activity, drugs which block the adrenergic receptors may be effective in the prophylaxis of migraine.

Indoramin (fig 1) is a selective alpha-adrenoceptor blocking drug $^{8}$ and is being investigated for its possible prophylactic value in migraine. ${ }^{9}$ In addition to alpha-adrenoceptor blockade, indoramin in higher concentrations also blocks the reuptake of released noradrenaline in the synaptic cleft. ${ }^{10}$ Tyramine is an indirectly acting sympathomimetic amine which releases noradrenaline from nerve terminals. ${ }^{11}$ Recently tyramine has been used to study the reuptake blocking-effect of tricyclic and related antidepressive drugs. ${ }^{12}$ One index of the various pharmacological actions of tyramine that can be conveniently studied is the increase in blood pressure (BP) induced by the released noradrenaline (tyramine-dose/pressor response test). ${ }^{13}$

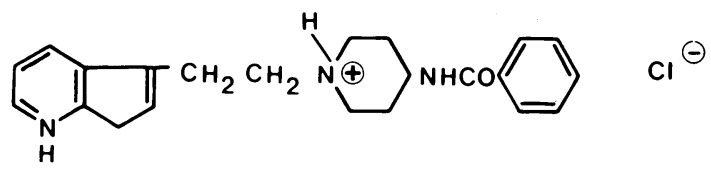

FIG 1-Structural formula of indoramin.

There were three main objects of the present investigation. Firstly, to compare the reaction of untreated migraine sufferers with control subjects to the intravenous tyramine-dose/pressor response test. Secondly, to evaluate the pharmacological interaction of indoramin on the tyramine-dose/pressor response test. Thirdly, to investigate the incidence of migraine after intravenous tyramine among migraine sufferers both before and during indoramin treatment.

\section{Patients and methods}

Thirty-one patients with migraine ( 20 women, $11 \mathrm{men}$ ), were selected according to the criteria of the World Federation of Neurology Research Group on Migraine and Headache. ${ }^{14} \mathrm{~A}$ full medical history was taken and particular attention was paid to possible precipitating factors of migraine, including diet and the relation of migraine to the menstrual cycle. Patients with a history of psychiatric and cardiovascular disorders and those with clinical electrocardiographic and electroencephalographic evidence of cardiovascular or other neurological illnesses were excluded from the study. The 27 control subjects 
(14 women, 13 men) were normal, healthy volunteers with no history of migraine or psychiatric illnesses. ${ }^{15}$ All participants were outpatients.

A double-blind crossover design was used, in which one group of patients received indoramin $10 \mathrm{mg}$ three times daily for one month and identical-looking placebo tablets for one month; the other group of patients received indoramin $20 \mathrm{mg}$ three times daily for one month alternating with the matched placebo tablets. Patients were randomly assigned to receive either placebo or indoramin first, and neither the investigators nor the patients were aware of the treatment schedules. The tyramine-dose/pressor response test was performed in the morning after the last tablet had been taken at 8 am, that is-about one and a half hours after the morning tablet. No other medication was allowed for at least 24 hours before the test. In women patients the test was repeated during the same phase of the menstrual cycles.

The patients were asked to volunteer for the investigation and gave informed consent on their previous visit to the clinic. On the morning of the investigations they rested for at least half an hour in the clinic and for another half an hour lying in bed before the tyramine-dose/ pressor response test. The test began when the resting BP became steady for at least 10 minutes. The intravenous tyramine-dose/pressor response test is described in detail elsewhere. ${ }^{13}$ Briefly, intravenous tyramine was given in a starting dose of $0.5 \mathrm{mg}$ and increased according to the systolic BP response. The aim was to increase the systolic $\mathrm{BP}$ by $30 \mathrm{~mm} \mathrm{Hg}$. From the dose-response curves the amount of tyramine required to increase the systolic BP by $30 \mathrm{~mm} \mathrm{Hg}$ was determined. After each test patients were asked to complete a standardised record of their migraine attacks and any other systemic reactions for three days after the tyramine-dose/pressor response test. These were studied during the two treatment periods-that is, during placebo and indoramin regimens.

\section{Results}

Placebo tablets-Both men and women with migraine required significantly less tyramine than the control subjects to increase their systolic BP by $30 \mathrm{~mm} \mathrm{Hg}$ (table I). There was no significant difference in the mean age of the two groups. Figure 2 shows the individual tyramine requirements in both migraine and control groups. There was a group of patients with migraine whose tyramine requirement was below the normal range.

Indoramin-There were two groups of patients who received either 30 or $60 \mathrm{mg}$ of indoramin daily for a month. Figure 3 shows that the drug significantly increased the requirements of tyramine to raise the systolic BP by $30 \mathrm{~mm} \mathrm{Hg}$. Patients receiving $60 \mathrm{mg}$ required more tyramine than patients receiving $30 \mathrm{mg}$. This difference, however, just failed to reach significance.

Effect of intravenous tyramine on migraine-In this study only patients who completed the standardised migraine record during both placebo and active medication were included. Table II shows the incidence of migraine after intravenous tyramine. Migraine attacks were graded from 0 to 3 in the following way: grade 0 represented no attack within 36 hours of injection; grade 1 an attack between 25 and 36 hours after injection; grade 2 an attack between 13 and 24 hours after injection; and grade 3 comprised attacks occurring within 12 hours after injection. Before treatment six patients $(46 \%)$ experienced headache after intravenous tyramine whereas during indoramin treatment only one $(8 \%)$ of these patients experienced migraine. This difference is significant at the $5 \%$ level using Fisher's exact probability test. None of the control subjects complained of headache after the tyramine-dose/pressor response test.

TABLE I-Mean tyramine dose required to increase systolic blood pressure by $30 \mathrm{~mm} \mathrm{Hg}$ in patients with migraine during the drug-free period and in a group of control subjects

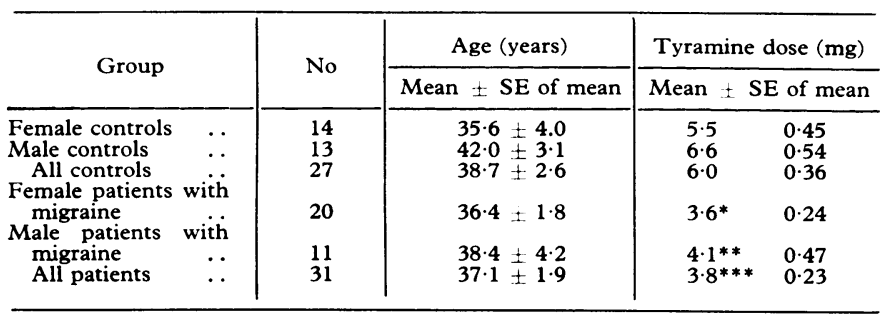

*Female controls $v$ female patients with migraine: $\mathrm{P}<0.05$ ** Male controls $v$ male patients with migraine: $\mathrm{P}<0.0$

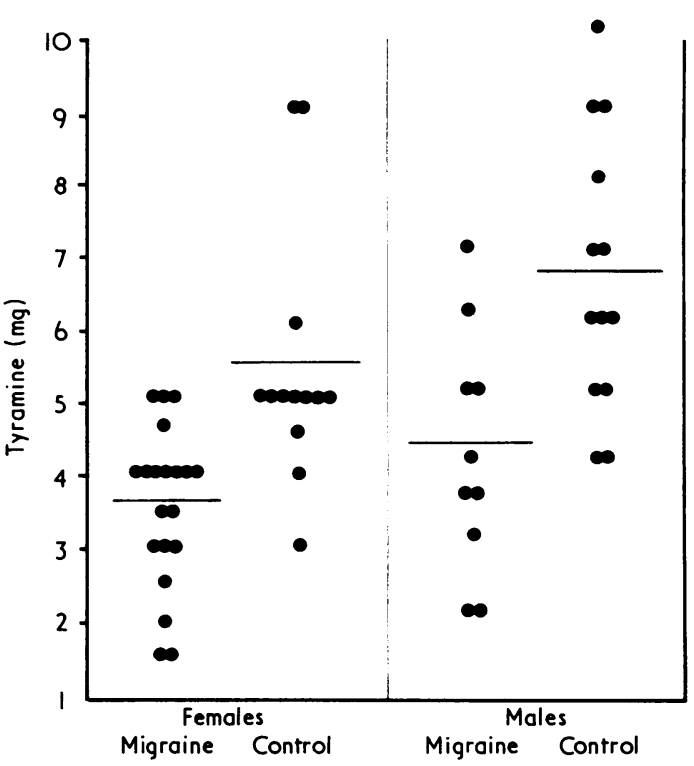

FIG 2-Tyramine dose (mg) required to increase systolic blood pressure by $30 \mathrm{~mm} \mathrm{Hg}$ in untreated patients with migraine and control subjects.

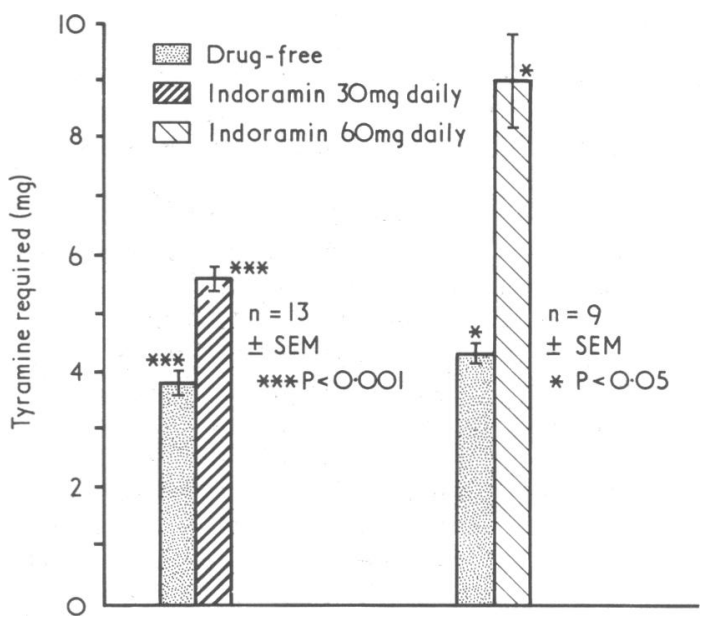

FIG 3-Increases in tyramine requirement among patients with migraine on indoramin.

TABLE II-Incidence of migraine attacks after intravenous tyramine among 13 migraine sufferers when receiving either placebo tablets or indoramin treatment

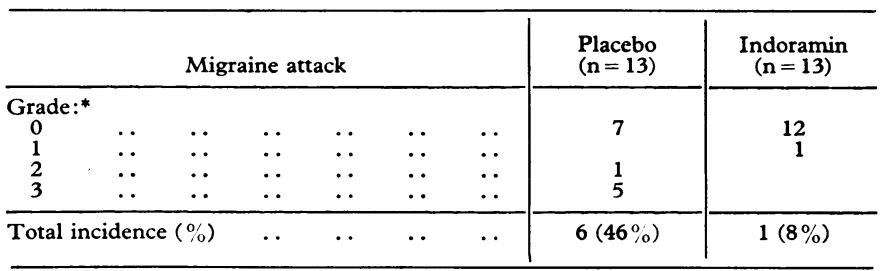

$P<0.05$ (Fisher's exact probability test)

* Grade $0=$ no attack within 36 hours of tyramine injection; grade 1 = attack $25-36$ hours after injection; grade $2=$ attack between 13 and 24 hours after injection grade $3=$ attack within 12 hours after injection.

Relation of post-tyramine headache to other precipitating factorsFactors that may have had a bearing on tyramine sensitivity were examined in these patients but no association was found between the occurrence of post-tyramine migraine and a history of migraine related to ingestion of tyramine-containing foods. Nor was there a significant relation between post-tyramine headache and a history of premenstrual headache. No significant difference was observed in the incidence of post-tyramine headache among male and female patients. 


\section{Discussion}

Our findings of increased sensitivity to the tyramine-dose/ pressor response test among migraine sufferers parallels closely our findings in depressed patients. ${ }^{15}$ An association between migraine and depression has been postulated by several investigators. ${ }^{1617}$ Both migraine ${ }^{134}{ }^{7}$ and depression ${ }^{1819}$ are reported to be associated with altered monoamine metabolism. Both conditions are clinically prevalent among women and have some association with the menstrual cycle. There is as yet, however, no conclusive evidence of a direct association between these two conditions. Increased tyramine sensitivity among migraine sufferers may be due to one or more factors-namely, an increase in adrenergic-receptor sensitivity; a decrease in monoamine oxidase activity; increased uptake of tyramine into noradrenaline-containing neurones; increased intraneuronal stores of noradrenaline and increased release of noradrenaline, or both Direct evidence to confirm the validity of these factors is absent or conflicting. The observation of decreased platelet monoamine oxidase activity among migraine sufferers, however, appears to be consistent with our findings.

The apparent induction of migraine by intravenous tyramine does not agree with the results reported after oral tyramine. ${ }^{6}$ Although we did not give the patients a placebo injection, no suggestion was made that the injection would induce headaches or migraine. Moreover, the appreciable reduction in the incidence of post-tyramine migraine on indoramin (given under double-blind conditions alternately with placebo) suggests that pharmacological rather than psychological precipitants were responsible for the post-injection migraine.

Our results show that either excessive release of noradrenaline or sensitivity to it may be a factor in some patients with migraine. We must emphasise that migraine may well be heterogeneous and there may be a subgroup of migraine sufferers who are sensitive to tyramine. The reduced incidence of post-tyramine migraine among patients on indoramin suggests that it may be an effective prophylactic agent. The intravenous tyramine test may be a valuable method of selecting patients who will respond to an alpha-adrenergic blocking agent such as indoramin.

\section{References}

1 Sicuteri, F, Background to Migraine, p 45. London, William Heinemann Medical Books, 1973.

2 Espin Herrero, J, and Barcia Marino, C, Medicina Española, 1974, 71, 65.

3 Sicuteri, F, Testi, P, and Anselmi, B, International Archives of Allergy and Applied Immunology, 1961, 19, 55.

${ }^{4}$ Curran, D A, Hinterberger, H, and Lance, J W, Brain, 1965, 88, 997.

5 Hannington, E, British Medical fournal, 1967, 2, 550.

${ }^{6}$ Ryan, R E, jun, Headache, 1974, 14, 43.

7 Sandler, M, Youdim, M B, and Hannington, E, Nature, 1974, 250, 335

${ }^{\circ}$ Variava, D H, and Turner, P, fournal of Pharmacy and Pharmacology, 1973, 23, 629.

${ }^{9}$ Carroll, $\mathrm{D}$, in preparation.

10 Sugden, R F, British fournal of Pharmacology, 1974, 51, 467.

11 Burn, J H, and Rand, M J, Fournal of Physiology (London), 1958, 144, 314

12 Siwers, B, et al, Abstract for Fourth International Congress on Pharmacology. Basel, 1969.

13 Ghose, K, et al, British fournal of Clinical Pharmacology, 1976, 3, 334

14 World Federation of Neurology's Research Group on Migraine and Headache, Hemicrania, 1969, 1, 3.

15 Ghose, K, Turner, P, and Coppen, A, Lancet, 1975, 1, 1317.

16 Couch, J R, Ziegler, D K, and Hassanein, R S, Headache, 1975, 15, 41.

17 Kashiwagi, T, McClure, J N, and Wetzel, R D, Headache, 1972, 12, 659.

${ }^{18}$ Schildkraut, J J, Neuropsychopharmacology and the Affective Disorders. Boston, Little, Brown, 1970.

19 Coppen, A, et al, Archives of General Psychiatry, 1972, 26, 474.

(Accepted 3 March 1977)

\section{SIDE EFFECTS OF DRUGS}

\section{Peripheral neuropathy: a side effect of sulphones}

To date there have been references to very few cases of peripheral neuropathy as a side effect of sulphone treatment. Most cases have been motor in type, ${ }^{12}$ but cases of sensory neuropathy ${ }^{3}{ }^{4}$ have also been described. During the past year two patients with peripheral neuropathy have been seen in our clinic, which seems to indicate that neuropathy as a side effect of sulphone treatment is not so rare as was once thought. The first patient ${ }^{4}$ developed symptoms of the distal extremity. The second patient is described here.

\section{Case report}

A 46-year-old man had dermatitis herpetiformis for 28 years. Since 1954 he was treated with sulfapyridine, but for unknown reasons he was placed on regimen of sulfoxone sodium $0.66-0.99 \mathrm{~g} /$ day, when needed. On average he received this medication two or three days a week. During the past year he has had the impression that his thumbs were sleeping during shorter or longer periods of time, irrespective of what he was doing or of other external circumstances. Sometimes the sensation became stronger and spread out over the hands to the ulnar side, but he did not notice any weakness in the affected hand Neurological examination showed nothing abnormal except for hypoalgesia in both thumbs. Electromyography showed nothing abnormal. The neuropathy disappeared when the drug was discontinued.

\section{Comment}

It seems likely that the higher the sulphone dose, the shorter the latency period before the symptoms occur. ${ }^{1-4}$ When the dose of sulphones is reduced, ${ }^{2}$ the symptoms of peripheral polyneuropathy abate gradually, indicating that neurotoxicity is dose-related. Once a patient has had symptoms of peripheral polyneuropathy ${ }^{4}$ he develops symptoms more rapidly when sulphones are readministered after a period of suspension.

1 Saqueton, A C, et al, Archives of Dermatology, 1969, 100, 214.

${ }^{2}$ Hubler, W R, and Solomon, H, Archives of Dermatology, 1972, 106, 598

3 Wyatt, E H, and Stevens, J C, British fournal of Dermatology, 1972, 86, 521.

4 Volden, G, Acta Dermatovenerologica, 1976, 56, 77.

(Accepted 24 September 1976)

Department of Dermatology, Rikshospitalet, Oslo, Norway G VOLDEN, MD, assistant physician

\section{Interaction between azapropazone and warfarin}

A Caucasian woman aged 59 underwent mitral valvotomy in 1967 for mitral stenosis. Three years later she had a cerebral embolus and was anticoagulated with warfarin. The dose was adjusted to keep the prothrombin ratio at 2.5. In February 1976 she complained of ulcer-type dyspepsia, and bariummeal examination showed a gastric ulcer, which was treated with Caved-(S) and antacids. The prothrombin ratio was then $2 \cdot 8$. She continued to take digoxin, frusemide, spironolactone, and allopurinol and no other medication until June, when her general practitioner prescribed azapropazone (Rheu$\mathrm{mox}$ ) in the recommended dosage of $300 \mathrm{mg}$ by mouth four times a day 